\title{
Order Backlog in Earnings Conference Calls
}

\section{By: Kate Suslava, Suresh Govindaraj, Ronen Feldman and Joshua Livnat}

\begin{abstract}
Firm disclosure of order backlog $(\mathrm{OB})$ is considered important to assess future sales and profits. The extant literature on $\mathrm{OB}$ has generally documented positive associations between increases in $\mathrm{OB}$ and market returns. These associations were based on annual disclosures of backlog in 10-K filings, and could have been caused by other simultaneous disclosures that were also correlated with order backlog. To focus on the direct effects of backlog on market participants, we use references to $\mathrm{OB}$ in earnings conference call transcripts. We find incremental market reactions to OB after controlling for earnings surprise and other information communicated during the conference call. Our findings also reveal that OB disclosures are more relevant when they are supported by numbers and when firms derive a material amount of their demand from OB.
\end{abstract}

Keywords: order backlog, conference calls, qualitative disclosures, stock returns.

JEL Classifications: G14, M41.

Data Availability: Data used in this study is available from public sources identified in the study. 


\section{Introduction}

This study investigates market reactions to disclosures and discussions of order backlog (OB) in earnings conference calls. It provides a unique setting to directly investigate the effects of OB on firms that chose to discuss their backlog in their earnings conference calls, or were prompted to answer questions about it by analysts on the call. In other words, our sample consists of firms whose managers or analysts considered OB important information. We investigate whether the disclosed information about $\mathrm{OB}$, some of which was only qualitative, is associated with immediate market reactions around the conference call, after controlling for earnings surprise and other information disclosed in the call. We further study whether market reactions in the short window after the call are complete, or whether a drift in market reactions occurs after OB is discussed.

Whether OB should affect firm valuation is not a trivial question. On the one hand, OB provides information about potential future sales, and is likely to be useful in forming expectations about future earnings and cash flows. However, as Rajgopal, Shevlin, and Venkatachalam (2003) show, investors may be overreacting to the implications of $\mathrm{OB}$, estimating that their effects on future earnings will extend beyond actual realizations, leading to negative future returns. In addition, OB reporting practices make it harder for investors to rely on $\mathrm{OB}$ disclosures when making valuation decisions. OB information is self-reported and unaudited; moreover, there are no accounting rules or disclosure standards that specify what should be included in OB. Unlike many other disclosures in financial statements, where comparability across firms and over time is reasonably achieved by accounting standards and external audits, OB practices can vary even within the same firm across segments and over time. Furthermore, the disclosure of $\mathrm{OB}$ is mandated by the Securities and Exchange Commission (SEC) only in annual 10-K Forms, and only if material. Prior studies of 
OB investigated these annual disclosures, and were typically unable to pinpoint the precise date on which OB became available to market participants.

In our study of $\mathrm{OB}$, we follow a different approach. We focus on those firms which address OB in their earnings conference calls. This approach has several advantages over prior studies. First, we know precisely when the information was disclosed to the market. Second, we can assume that the information is important if managers chose to discuss it on their calls, or if analysts inquired about it. Third, the information we use is from quarterly earnings calls, while some of the annual surprise in OB used by prior studies may have been inferred by market participants through earlier quarterly disclosures. Fourth, we study not only quantitative disclosures of $\mathrm{OB}$, but also qualitative statements about it without any numerical values. This information has not been used by prior studies of $\mathrm{OB}$, and to obtain this information we use advances in Natural Language Processing (NLP).

We find that investors react to $\mathrm{OB}$ disclosures and discussions in the short window around the earnings conference call date. These reactions are manifested after controlling for the contemporaneous earnings surprise and the general tone of the conference call itself. However, we find that the subsequent drift in returns is related to the general tone of the earnings conference call, but not to earnings surprise, OB tone, or the short-window return around the conference call. Thus, investors seem to react fully to OB information in earnings conference calls at the time of its disclosure. In additional tests, we show that these market reactions hold for both levels (OB tone in a given quarter) and changes of $\mathrm{OB}$ disclosures ( $\mathrm{OB}$ tone in a given quarter relative to historical $\mathrm{OB}$ tone). We also examine the value of numerical $\mathrm{OB}$ disclosures during earnings calls and find that managers can mitigate investor overreaction to $\mathrm{OB}$ tone by supplementing qualitative OB disclosures with quantitative backlog information. Finally, we examine the relevance of OB 
disclosures cross-sectionally and find that $\mathrm{OB}$ tone is especially relevant for firms that derive a significant amount of their demand from OB.

The remainder of the paper is organized as follows. In Section 2, we review the literature and develop our predictions. Section 3 describes the sample, our NLP tool that identifies OB (and the general tone) in earnings conference calls, as well as other data and variables used in the study. Section 4 presents and discusses the results and the last section concludes.

\section{Literature Review and Predictions}

\subsection{Prior Literature}

OB consists of contractual orders that have not yet been fulfilled by a firm, but are expected to be fulfilled and reported as sales in future periods. As noted by Rajgopal et al. (2003), OB is estimated to be about $30 \%$ of total assets for the median sample firm that reports OB, thus making it economically significant. Therefore, it seems intuitive that OB should be widely used by both analysts and forecasters to predict future firm sales and earnings, as well as by investors to predict future returns. It is important to point out that even though OB is likely perceived as a valuerelevant disclosure, the reporting of $\mathrm{OB}$ is not currently a part of required audited financial statements, nor is OB disclosure required in quarterly SEC filings. ${ }^{1}$ OB is mandated by the SEC only in the annual Form $10-\mathrm{K}^{2}$. However, some companies choose to disclose information about

\footnotetext{
${ }^{1}$ Auditors review OB as part of their review of supplemental information, a requirement governed by AS 2701 Auditing Supplemental Information Accompanying Audited Financial Statements. The audit standards do not specifically relate to $\mathrm{OB}$ and are designed to assure reasonableness and completeness of the supplemental information.

${ }^{2}$ SEC requirements regarding OB disclosures are outlined in item 101 (Description of Business) of Regulation S-K. According to Section (c), subsection (VIII) of Item 101, companies should disclose: (1) the dollar amount of backlog orders believed to be firm, as of a recent date and as of a comparable date in the preceding fiscal year, (2) an indication of the backlog portion that is not reasonably expected to be filled within the current fiscal year, (3) seasonal or other material aspects of the backlog. The requirement also states that firm orders can include governmental orders that are
} 
their backlog either in quarterly filings (Form 10-Q), in their preliminary earnings press release (which since 2004 must be filed in a Current Report, Form 8-K), or in their quarterly conference calls. Voluntary OB disclosure can be either quantitative or qualitative, further complicating the interpretation of the disclosure for future sales and earnings.

Prior empirical research on the relationship between $\mathrm{OB}$ and market returns has shown contradictory results regarding both its significance and direction. Lev and Thiagarajan (1993) identify annual, quantitative OB disclosures as one of 12 fundamental signals commonly used by analysts to determine the value of a firm's stock (their OB signal is defined as the percentage change in annual sales less the percentage change in annual OB). They interpret $\mathrm{OB}$ growth contextually, by not only controlling for sales growth, but also by controlling for other fundamentals including the macroeconomic climate. They show that a larger (smaller) increase in OB relative to the increase in sales is viewed positively as increasing (decreasing) future demand for the firm's products and increasing (decreasing) the value of the firm's stock. Behn (1996) is one of the earliest authors to investigate and provide persuasive evidence that the change in $\mathrm{OB}$ (annual change in OB scaled by the market value of equity) also provides investors with useful information about future earnings and annual stock returns.

Rajgopal et al. (2003) focus on OB levels (their OB signal is the year-end OB level scaled by average total assets) and investigate whether the stock market efficiently values annual quantitative OB disclosures. Using the well-known Mishkin test (1983) of market efficiency, they show that the market overestimates the importance and value of OB-level disclosures on future earnings, and

firm but not funded and contracts awarded but not yet signed, provided an appropriate statement is added to explain the nature of such orders and the amount thereof. The portion of orders already included in sales or operating revenues on the basis of percentage of completion or program accounting shall be excluded. 
consequently misprices firms. To further corroborate this, and to blunt criticism that testing efficiency of financial markets is a joint test of model specification, Rajgopal et al. (2003) follow the Fama-MacBeth method (1973) of constructing zero-investment portfolios, using short and long positions in deciles of $\mathrm{OB}$ levels to show that $\mathrm{OB}$ signals and future returns are negatively related. They conclude that investors overvalue OB disclosures.

A working paper by Gu, Wang, and Ye (2008) does not find evidence corroborating the findings of Rajgopal et al. (2003) that market investors overestimate the value of the level of OB signals. However, they do find evidence that investors underestimate the value relevance of the change in OB (annual change in OB scaled by the total assets). While their finding is consistent with the earlier finding of Behn (1996) regarding the value relevance of changes in OB, their work is also limited to annual disclosures of OB and to annual returns. Francis, Schipper, and Vincent (2003) examine the usefulness of $\mathrm{OB}$ for the homebuilding industry: they examine both the OB level (scaled by the market value of the firm's equity) and the OB change (annual change in OB scaled by the market value of the firm's equity). They find little evidence that either the level or the change of the OB signal is informative about future firm performance, especially after controlling for earnings disclosures. Gu and Huang (2010) use annual OB disclosures to construct an OB factor (annual change in OB scaled by the total assets) at the portfolio level and show that this factor can be used to explain portfolio momentum returns. They find that winner stocks (high momentum stock portfolios) have higher positive changes in $\mathrm{OB}$, while losers (low momentum stock portfolios) experience the opposite. They also find that the OB factor is positively related to future growth in sales, investments, dividends and returns for the winner and loser portfolios. Finally, a recent working paper by Toynbee (2018) examines the usefulness of the OB 10-K disclosure requirement by contrasting forward-earnings response coefficients for OB disclosers 
and non-disclosers and finds that these disclosures are mostly informative when OB is a relevant signal of demand.

In summary, the existing literature offers conflicting views about the potential information content of annual OB disclosures to investors and the market values of firms. This may be due to limited information about the exact timing of annual OB disclosures, the existence of other information that may be correlated with $\mathrm{OB}$ and the inconsistencies in $\mathrm{OB}$ factor definitions.

\subsection{Our Study}

We chose to focus on $\mathrm{OB}$ disclosures and discussions in earnings conference calls for several reasons. First, it seems reasonable to assume that OB disclosures in conference calls are provided when either management or analysts consider them important. Second, the precise date of disclosure is known, enabling us to consider both short-window returns and drift returns. Third, unlike prior studies that were limited to annual quantitative $\mathrm{OB}$ disclosures, we are able to capture qualitative and quarterly OB disclosures, as well. In our study, we use NLP rules to identify the "tone" of $\mathrm{OB}$ disclosures and discussions. When $\mathrm{OB}$ figures are provided for the most recent quarter along comparable figures for prior periods, our NLP rules capture OB increases (decreases) as positive (negative) tones. We also assign a positive or negative tone to qualitative $\mathrm{OB}$ disclosures, as we describe in the next section.

Recently, the utilization of qualitative information extracted from earnings conference calls has become prevalent, with most studies providing evidence that conference call transcripts provide value relevant information to investors. Early studies of conference calls examined the overall impact of these qualitative disclosures on investors' trading behavior. Frankel, Johnson, and Skinner (1999) show that large institutional investors trade during earnings calls. Bushee, 
Matsumoto and Miller (2003) find that providing investors with real-time access to the content of conference calls ("open" calls) is associated with an increase in small trades, suggesting that individual investors also trade on the information contained in the conference calls. Matsumoto, Pronk and Roelofsen (2011) measure absolute returns during each call segment (management discussion and Q\&A session) and show that both sections of the call provide value-relevant information to market participants. Subsequent research of earnings calls used applications of content analysis to extract and quantify call tone and showed a directional association between this measure and market returns. Price, Doran, Peterson, and Bliss (2012) show that tone measures based on the Harvard (Harvard IV-4 Psychosocial) and Henry (2008) dictionaries are significantly related to immediate abnormal returns, post-earnings announcement drift and abnormal trading volume. Brockman, Li, and Price (2015) use the Loughran and McDonald (2011) dictionary to quantify the tone of earning calls and find that both managers' and analysts' tones have a directional association with abnormal market returns.

Given the earlier results about information disclosed in conference calls and most of the literature on $\mathrm{OB}$, we predict that the $\mathrm{OB}$ tone we extract from earnings conference calls will be positively and significantly associated with immediate market returns around the conference calls. Since the conference calls provide substantially more information to investors, we need to control for the earnings surprise and other information in our tests. Whether OB tone is significantly related to short-window returns is far from clear, a priori. First, the other information disclosed in the conference call or the earlier earnings release may overwhelm OB disclosure. Second, our measure of OB tone may be too noisy to be associated with market returns. Third, investors may be hesitant to react to quarterly $\mathrm{OB}$ disclosures, which are subject to greater seasonality than annual $\mathrm{OB}$ disclosures. 
Our second objective is to study the association between OB tone and drift returns. We do not make a directional prediction about the the relationship between $\mathrm{OB}$ tone and subsequent returns, however, for two reasons. On the one hand, Rajgopal et al. (2003), show that the market overestimates the future earnings implications of annual quantitative OB signals, as evidenced by the negative relationship between drift abnormal returns and their OB signals. It is reasonable to assume that investors might also be overestimating OB tone, similar to the overreaction observed for quantitative $\mathrm{OB}$ signals. On the other hand, prior research shows that investors tend to underreact to qualitative information contained in conference calls (Lee, 2016). Since our OB signal is based on conference call OB discussions, investors might not fully and immediately incorporate this information into stock prices. Finally, it is also possible that the relation between OB tone and drift returns is insignificant, if investors fully incorporate the tone of these disclosures into their immediate pricing decisions.

Our NLP rules allow us to capture not only qualitative, but also quantitative OB disclosures. We use this data to test the importance of supporting OB statements with numbers. Zhou (2016) shows that managers tend to use more numbers during earnings calls when companies perform well, and that a higher proportion of quantitative information is associated with positive immediate and drift abnormal returns. We hypothesize that since OB discussions including numbers are more precise and present less ambiguous information about OB to investors, these types of disclosures should result in higher market returns.

Prior studies find mixed evidence about the usefulness of OB (e.g., Francis et al., 2003; Gu et al., 2008). Following up on this, Toynbee (2018) questions the relevance of the blanket SEC OB disclosure requirement, and finds some evidence that $\mathrm{OB}$ information might be more useful for firms that have a lag between receiving and fulfilling orders. In her study of quantitative annual 
OB disclosures, Toynbee separates her sample of firms into make-to-order (firms that begin production after they receive an order) and make-to-stock (firms that produce goods to hold in inventory), and finds that $\mathrm{OB}$ is a less informative disclosure for make-to-stock firms. We extend the Toynbee (2018) study and test whether her findings hold in the setting of qualitative quarterly disclosures, as well. We expect that the quarterly OB tone is a more relevant signal for make-toorder firms than for make-to-stock firms.

\section{Data, Variables and Research Design}

\subsection{Tone Extraction}

There are three main methodologies to extract tone (assign a numeric value) from a text. The first is the so-called dictionary method, based on counting the number of positive and negative words in a document (Feldman, Govindaraj, Livnat, and Segal, 2010; Loughran and McDonald, 2011; Price et al., 2012). The second is based on labeling sentences (or paragraphs, or even entire documents) as positive or negative, and using classification techniques to predict whether the tone of the current document is positive or negative, depending on the sentences or paragraphs that it contains ( $\mathrm{Li}, 2010)$. The third approach is to write specific NLP rules to identify phrases or events of interest in a text. For example, one can write specific rules to identify mergers or earnings guidance based on the syntax of a sentence that conveys information about mergers or earnings guidance. This task is complex, because the text may be related to acquisitions, joint ventures,

alliances or similar arrangements. Similarly, apparent earnings guidance may actually be related to other items, such as revenues, or to strategic initiatives by the firm. Thus, to increase accuracy of the extraction process in the third approach, the extraction is based on many specific rules that are used to identify the event of interest. 
In our study, we rely on software developed by Amenity Analytics, a company that specializes in text mining (https://www.amenityanalytics.com/). The software (“Amenity") comes with a rich dictionary of sentiment words and phrases, which include the Loughran and MacDonald (2011) dictionary plus a 10-year accumulation of other sentiment-relevant words and phrases that are relevant for business-related text. The software also includes about 3,000 NLP rules that are used to extract over 60 different events, such as financial results, product announcements, earnings guidance, etc. Each event is assigned a polarity, e.g., revenue, and income increases are considered positive, whereas expense and liability increases are considered negative. Each sentiment word or phrase is assigned a weight (typically 1), and each event is assigned a weight between 1 and 10, depending on its importance for investors. After processing a document, we determine the tone of the document as the total positive score (POS) minus the total negative score (NEG), divided by its sum (POS+NEG).

A useful feature of Amenity is that it allows the creation of NLP rules by a user who is a domain expert but not an NLP expert. The user highlights a sentence, which the software parses into a graph. The user can then eliminate parts of the sentence that are not required (such as the name of a person or entity because they are too specific, or peripheral items that are not required for the rule) by clicking on these items. The user then unleashes the rule on a small corpus of documents to find other examples of that rule. If an insufficient number of examples are extracted, the user needs to eliminate more parts of the graph and/or select more synonyms for the essential parts of the sentence. Once the user is satisfied with the breadth and accuracy of the retrieved examples, the rule is saved and is subsequently used to process a large corpus of documents.

We used Amenity to write rules that extract backlog discussions from the earnings calls. First, we selected a subsample of 100 random earnings call transcripts and uploaded them into Amenity's 
Graphic User Interface. The software automatically performs the following types of text annotation: part-of-speech, syntax and semantics. Part-of-speech annotation that tags each word according to its word class (for example, noun, adjective, verb or adverb) assists with word sense disambiguation. For example, the word "order" can be either a noun or a verb. For our project, it was important to capture "order" specifically as a noun phrase, such as "order backlog." Syntax tagging decomposes a sentence into its constituents (for example: subject, predicate, object) to show how the grammatical arrangement of words forms a sentence. This type of tagging further helps address word ambiguity at a sentence level by showing the syntactic relation to each word/phrase. Amenity automatic syntax tagging allows human coders to write rules that extract precise backlog events from wordy sentences. For example, in the sentence "We've been working on some, what's a nice way to say it, 'less attractive backlog," Amenity tags "we" as a sentence subject, "work" as a predicate, "backlog" as an object, and "less attractive" as an adverbial modifier to "backlog." The conversational cliché phrase: "What's a nice way to say it?" is tagged as a separate subordinate clause that is excluded from the main clause. Finally, Amenity has a number of pre-programmed semantic taggers (Named Entity Recognition tags - NER tags) that assign meaning to individual words or phrases based on their most likely use in the language of financial reporting. For example, it has a NER tag, "Revenue," which includes words such as "revenue," "sales," "profit" and "gross profit," and a NER tag "Expense," which contains "cost of goods sold," "selling expenses," "tax expense" and "interest expense." NER tags allow for the creation of more generalized rules that, for example, assign a negative (positive) sentiment to the NER tag "Expense," when it is followed by a verb, e.g., "increase" ("decrease"). For our project, we used the NER tag "Money," which recognizes any numeric value with a dollar sign as a monetary entity and NER tag "Date," which has a dictionary of various ways to describe a specific 
point in time. For example, in the sentence "Our backlog stands at $\$ 170$ million," Amenity tags "\$170 million" with a Money NER tag and extracts the amount in a separate category. The NER tag Date is useful in sentences such as: "Backlog is less than in the first quarter," as Amenity tags "the first quarter" with the NER tag Date, and allows a human coder to create a general rule that classifies this event as negative when the phrase "Backlog is less than" is followed by any type of date.

Next, human coders read the transcripts to find backlog mentions, create rules that capture these discussions and assign a sentiment to each rule as either Positive, Negative or Neutral. For example, the following sentence "We experienced a decline in our backlog in 2018" was used to create a rule with two lemmas, "decline" and "backlog," connected with a preposition "in," and then assigned a negative sentiment. Another example is the sentence "So to sum up, we have a healthy backlog and a solid financial position" that was used to create a rule including lemmas "have" as a predicate, "backlog" as an object, and "healthy" as an adjective modifier, and which was assigned a positive sentiment. Finally, some sentences were used to extract backlog levels and were assigned a neutral sentiment. For example, the sentence "Your current backlog stands at $\$ 2.3$ million" was used to create a rule with lemmas "backlog," "stand" and "at," as well as NER tag Money. Overall, human coders wrote 86 backlog extraction rules. Next, we applied the set of backlog rules to the conference call corpus using the Amenity batch process, which calculates how many times each rule occurs in each transcript. Using the output, we calculated the overall backlog score $(B K L)$ as the total number of $\mathrm{OB}$ mentions with positive polarity, less the total number of OB discussions with negative polarity, scaled by the total count of OB mentions (positive, negative, and neutral) for each transcript. We also used the NER tag Money extractions to determine the presence of numerical backlog mentions (NUM). 


\subsection{Data, Variables and Sample}

We obtained conference call transcripts from Thomson Reuters for the period 2002-2018. We concentrated only on earnings conference calls, which contained the word earnings in the heading, and eliminated those calls that did not occur within one day of the earnings announcement date in the quarterly Compustat file. We obtained financial data, such as book value of equity, total assets and market value of equity at month-end, prior to the conference call from Compustat. Earnings surprises were calculated by using data from I/B/E/S and stock return data was from the Center for Research in Securities Prices (CRSP).

We first processed all earnings conference call transcripts to determine their overall tone according to the sentiment and event rules supplied by Amenity. ${ }^{3}$ We also extracted all backlog-related tone according to the special rules we had written. We assigned a total tone score (TONE) to a particular transcript based on the ratio of (POS-NEG)/(POS+NEG), which is a number in the range of [$1,+1]$. We followed a similar procedure for the backlog tone $(B K L)$, except that neutral backlog events were added in the denominator to account for the overall extent of OB discussions. We also explicitly kept track of whether the backlog disclosure contained quantitative information or only qualitative $(N U M)$.

To estimate the earnings surprise we used the actual EPS from I/B/E/S minus the mean forecast of quarterly earnings that were made in the 90-day period prior to the earnings announcement date, where we retained only the most recent forecast for each analyst during that period. We used two variables to scale the earnings surprise: $S U E A F 1$ is scaled by the standard deviation of all forecasts

\footnotetext{
${ }^{3}$ We avoided using Amenity rules related to $\mathrm{OB}$ at this stage.
} 
during the 90-day period (with a minimum of 0.01 ), and SUEAF2 is scaled by the price at monthend prior to the earnings announcement date.

We calculated the abnormal return in the short window (XRET_PRELIM) around earnings announcement (day 0 ) as the buy and hold return on the stock during the interval $[-1,+1]$ minus the value-weighted buy and hold return of similar companies in terms of size (market value, 3 groups), Book/Market (3 groups) and 11-month momentum ([-12, -2], 3 groups). Drift returns (XRET_DRIFT) were the abnormal buy and hold returns in the period [+2, NEA+1], where NEA was the next quarterly earnings announcement date, if known, or 90 if missing.

In our regression models, we used the abnormal returns as the dependent variable and the scaled backlog tone as the main independent variable. We ranked the backlog tone variable into quartiles within a quarter (a number between 0 and 3), divided by 3 and subtracted 0.5 to transform the variable into a number in the range $[-0.5,+0.5]$. The coefficient on the transformed backlog tone can be interpreted as the return on a hedge portfolio that holds long positions in the most positive tone quartile and short positions in the most negative one. For the regression analysis, we also transformed SUEAF1, SUEAF2, and TONE between -0.5 and 0.5 by ranking them into the deciles ( 0 to 9 ) by fiscal quarter, dividing the rank by 9 , and subtracting 0.5 . We added controls for size (ASSETS, calculated as the log of total assets), growth (BM, book-to-market ratio), and uncertainty (STD_EARN, the standard deviation of quarterly earnings forecasts in the 90-day period prior to the earnings announcement).

Figure 1A shows the number of earnings conference call transcripts we processed quarterly, and Figure 1B plots the percentage of those with $\mathrm{OB}$ disclosures. The total number of quarterly earnings calls increased over the years: it includes about 700 calls a quarter in 2002 and grows to 
over 3,000 a quarter in 2016-2017. While this increase is partially due to expanded coverage from the data provider, it mainly reflects the effects of Regulation FD, which mandates companies to disseminate any material information disclosed to analysts to the public (Mayew 2008). The proportion of calls that mention OB fluctuates between 13-19\% of all calls, which is about half of all companies in Compustat that provide mandated annual disclosures in their $10-\mathrm{K}$ filings (approximately 36-40\%). This finding indicates that while OB remains a material voluntary disclosure, call participants might consider it not particularly useful for some companies. This is consistent with findings by Toynbee (2018) that OB is not relevant for all firms that disclose it in mandated annual filings.

\section{Empirical Results}

\subsection{Descriptive Statistics}

We find that, on average, earnings calls have two positive OB mentions per transcript and less than one (around 0.5) negative or neutral OB mentions. Panel A in Table 1 reveals that the aggregated OB score $(B K L)$ is on average positive with the mean (median) at $0.57(1.00)$ and that roughly half of all calls make quantitative disclosures of $\mathrm{OB}$ (the mean for $N U M$ is 0.54 ). The standard deviation of $B K L$ is substantial at 0.60 and an examination of its distribution suggests that $B K L$ frequencies exhibit substantial skewness caused by outliers. The top two quartiles of conference calls have mostly positive $\mathrm{OB}$ tones, as some calls within this group contain a substantial number of positive OB mentions (upwards of 24 (only 12) positive (negative) OB mentions per conference call). The quarterly changes in $\mathrm{OB}$ mentions $\left(C H \_B K L\right)$ is minimal, on average, (mean (median) is -0.01 (0.00)), but exhibits a substantial variation: the standard deviation is 0.64 . It appears that call participants mostly keep OB discussions positive from period to period, and change these 
disclosures infrequently. Overall, earnings calls have a positive sentiment (TONE): the mean (median) is $0.37(0.39)$ and the number of positive words exceeds the number of negative words even in the lower quartile (P25 is at 0.21$)$. The tone optimism is consistent with prior findings that managers are likely to promote firm performance on these calls due to lower litigation risk and regulatory restrictions compared to other forms of corporate communication.

Panel B in Table 1 reports the Spearman correlation of OB measures with firm characteristics. There is a significant positive correlation between both backlog tone and the overall tone $(0.22)$ and the change in tone (0.12). Similarly, more optimistic OB tone $\left(C H \_B K L\right)$ is also positively correlated with both tone level and tone changes (correlation of 0.09 with TONE and 0.17 with CH_TONE). Firms with positive earnings surprises tend to have more optimistic OB tone (positive and significant correlation of 0.03 between $S U E A F 1$ and $B K L)$. Finally, there is a positive correlation between $\mathrm{OB}$ measures and the market reaction immediately after the call (the correlation coefficient with $X R E T \_P R E L I M$ is 0.06 and significant for both $B K L$ and $C H \_B K L$ ) and in the three-month period after the call (correlation coefficient with XRET_DRIFT ranges from of 0.01 to 0.02 ). Overall, these findings seem to indicate that, on average, positive OB disclosures in earnings calls is considered good news and investors recognize these qualitative disclosures in their investing decisions.

\subsection{Market Reaction to the Backlog Disclosures in the Earnings Calls}

Next, we use our sample of quarterly earnings transcripts to examine the market reaction to OB disclosures as reflected in the immediate abnormal three-day returns around the call date, as well as in the 90-day period of returns following the call. The following regression models are used to test these relations (see Appendix 1 for variable definitions); the standard errors are clustered by firm and year-quarter following Petersen (2009) and Gow et al. (2010): 
XRET_PRELIM ${ }_{j, t}=\beta_{0}+\beta_{1} B K L_{j t}+\beta_{2}$ TONE $_{j t}+\beta_{3} S U E A F_{j t}+\beta_{4} \log (\text { Assets })_{j t}+$

$\beta_{5} B M_{j t}+\beta_{6} S T D_{-} E A R N_{j t}+\varepsilon_{j t}$

$X_{\text {XRT_DRIFT }}, t=\beta_{0}+\beta_{1} B K L_{j t}+\beta_{2}$ TONE $_{j t}+\beta_{3} S U E A F_{j t}+\beta_{4} \log (\text { Assets })_{j t}+$

$\beta_{5} B M_{j t}+\beta_{6} S T D_{-} E A R N_{j t}+\beta_{7} X R E T_{-} P R E L I M_{j t}+\varepsilon_{j t}$

If the tone of $\mathrm{OB}$ discussions on conference calls changes investors' pricing decisions, we expect to see a significant positive coefficient on our main variable of interest $-B K L$ in Regression (1). Additionally, if investors underreact (overreact) to the tone of OB mentions, we expect to see a significant positive (negative) coefficient on BKL in Regression (2).

The results of estimating Regression (1) are presented in columns [1] and [2] of Table 2; we present the results for the regressions with two measures of earnings surprises - SUEAF1 and SUEAF2. The coefficient on $B K L$ is positive at 0.0085 (columns [1]) and 0.0089 (columns [2]) and significant at one-percent level (t-statistics $=3.84$ for column [1] and t-statistics $=3.97$ for column [2]). This suggests that, first, $\mathrm{OB}$ investors react to $\mathrm{OB}$ mentions and, second, that they recognize the direction of $\mathrm{OB}$ tone discussions in their pricing decisions around the conference call date. Regarding economic significance, these results indicate that firms in the top quartile of OB tone (most positive $\mathrm{OB}$ tone) earn about $0.8 \%$ higher returns relative to the firms in the bottom quartile (most negative OB tone). The control variables suggest that earnings calls with more positive overall tone and higher earnings surprises earn higher immediate returns: in column [1], for example, the coefficient on TONE is 0.0399 (t-statistics=16.70) and SUEAF1 is 0.0848 (tstatistics $=25.95)$.

Next, we test whether investors fully react to OB tone at the time of the earnings calls. Columns [3] and [4] of Table 2 report the results of estimating Regression (2). The coefficient on BKL is 
negative at -0.0026 (column [3]) and -0.0027 (column [4]), but not significant (t-statistics $=-0.56$ for column [3] and t-statistics $=-0.58$ for column [4]), indicating that investors do not over- or underreact to the OB tone. Our proxy for overall call sentiment is positively and significantly associated with subsequent abnormal returns: for example, in Column [3] the coefficient estimate on TONE is 0.0177 (t-statistics=2.98). This suggests that investors underreact to the qualitative information disclosed on the calls, as their immediate market reaction does not fully incorporate the tone of the call. With respect to economic significance, firms in the top decile of TONE earn $1.8 \%$ higher subsequent abnormal returns compared to firms in the bottom decile. Another interesting finding from columns [3] and [4] of Table 2 is the absence of significance for both measures of earnings surprises (both $S U E A F 1$ and $S U E A F 2$ ), which is inconsistent with prior findings that earning surprises tend to be positively and significantly associated with subsequent returns.

Overall, the evidence is consistent with our first prediction. The results found in Table 2 suggest that investors interpret positive $\mathrm{OB}$ tone as a positive signal and use it in their investment decisions. We do not, however, find any evidence of investor under- or overreaction to OB tone suggesting that investors fully react to it at the time of the call.

\subsection{Market Reaction to the Changes in OB Disclosures in the Earnings Calls}

The second set of tests investigates whether changes in OB tone are also reflected in abnormal stock returns. Prior studies point out that changes in qualitative corporate disclosures may be a more relevant measure, as these disclosures might not vary significantly from period to period and choice of words depends on a specific industry and company (Feldman et al., 2010). To address this concern, we perform a set of tests, using the changes of $\mathrm{OB}$ tone $\left(C H \_B K L\right)$ calculated as the 
difference between $B K L$ in the current quarter and the average $B K L$ measure in the previous four quarters. Specifically, we estimate Regressions (3) and (4):

XRET_PRELIM $_{j, t}=\beta_{0}+\beta_{1} C H_{-} B K L_{j t}+\beta_{2} C H_{-} T O N E_{j t}+\beta_{3} S U E A F_{j t}+$

$\beta_{4} \log (\text { Assets })_{j t}+\beta_{5} B M_{j t}+\beta_{6} S T D_{-} E A R N_{j t}+\varepsilon_{j t}$

XRET_DRIFT $j_{j, t}=\beta_{0}+\beta_{1} C_{-} B K L_{j t}+\beta_{2} C H_{-} T O N E_{j t}+\beta_{3} S_{U E A F_{j t}}+\beta_{4} \log (\text { Assets })_{j t}+$

$\beta_{5} B M_{j t}+\beta_{6} S T D_{-} E A R N_{j t}+\beta_{7}$ XRET_PRELIM $M_{j t}+\varepsilon_{j t}$

We use the same controls and specifications as in Regressions (1) and (2) except for the TONE variable; we substitute this variable with a measure of tone change $\left(C_{-} H_{T O N E}\right)$, which is calculated as the difference between the sentiment signal in a company's quarterly call and the mean sentiment signal in the company's conference calls held within the previous four quarters.

Columns [1] and [2] of Table 3 present the results for immediate abnormal stock returns. The coefficients on $C H \_B K L$ are positive (0.0072 for Column [1] and 0.0078 for Column [2]) and significant for both specifications (t-statistics=3.87 for Column [1] and t-statistics=4.06 for Column [2]). The coefficient estimates suggest that firm calls in the top quartile of $C H \_B K L$ measure (the highest increase in the optimism of OB disclosures) earn $0.7-0.8 \%$ higher returns relative to firms in the bottom quartile. This result is consistent with our findings for $B K L$ in the previous section and suggests that, similar to the higher levels of OB tone, investors view increases in OB tone as good news. Our measure of tone changes $\left(C_{-} H_{T} \mathrm{TONE}\right)$ and both measures of earnings surprises (SUEAF1 and SUEAF2) are positively and significantly associated with immediate abnormal market returns. The economic significance of these two signals is comparable: firms in the top decile of $C H \_T O N E$ (SUEAF) outperform firms in the bottom decile by $5.3 \%$ (8.3\%). 
Columns [3] and [4] of Table 3 present the results of estimating Regression (4) and report a negative but not statistically significant relationship between $C H \_B K L$ and XRET_DRIFT. Our measures of earnings surprises are similarly insignificantly associated with future abnormal returns. However, the coefficient on the measure of sentiment changes $\left(C H \_T O N E\right)$ is positive (0.0340) and significant at 1 percent level $(\mathrm{t}$-statistics=4.91). This result is consistent with the result for the tone levels in the previous section and suggests that investors, on average, underreact to the qualitative information disclosed on earnings calls.

Overall, the evidence for OB tone changes support our previous findings for OB levels. Investors view increases in $\mathrm{OB}$ tone as good news and fully react to these qualitative disclosures at the time of the call.

\subsection{Investor Reactions to OB Disclosures with Numbers}

We further study the information content of OB tone by parsing our sample into OB discussions with and without quantitative disclosures. We predict that since OB discussions with numbers are more precise, these types of disclosures should result in higher market returns. To test this prediction, we modify Regressions (1) and (2) by adding a dummy variable (NUM) equal to 1 if OB discussions mention the dollar amount of backlog and zero otherwise, and an interaction of $N U M$ with $B K L$. The main independent variable of interest in this test is the interaction term $(B K L * N U M)$, which captures the market effects of discussing OB with the help of quantitative OB information. We expect it to be positive and significant if investors view $\mathrm{OB}$ discussions supplemented by quantitative disclosures as more useful for their pricing decisions.

Columns [1] and [2] of Table 4 report the results of estimating regressions of immediate abnormal stock returns on our backlog signal $(B K L)$, the indicator for quantitative OB disclosures $(N U M)$, 
their interaction $(B K L * N U M)$ and the same controls as in Regression (1). Our proxy for the tone of $\mathrm{OB}$ discussions $(B K L)$ remains positive and significant (at 5 percent level): its coefficient is 0.0065 for Column [1] and 0.0067 for Column [2]. The indicator of quantitative OB disclosures $(N U M)$ and its interaction with tone are positive, but not significant for immediate pricing decisions. This evidence does not seem to support our prediction that investors find OB tones with quantitative disclosures more useful in their valuation decisions around the call date. The control coefficients on TONE and both measures of earnings surprise remain positive and significant, which is consistent with the results in Tables 2 and 3.

An examination of relation between $\mathrm{OB}$ tone measures and future abnormal returns reveals a different set of results, however. The results in Columns [3] and [4] of Table 4 indicate a negative association between OB tone and XRET_DRIFT: the coefficient on BKL is negative at -0.0153 and statistically significant ( $\mathrm{t}$-statistics=-2.03). This suggests that, controlling for quantitative $\mathrm{OB}$ disclosures, investors, on average, overreact to the $\mathrm{OB}$ tone at the time of the call and this overreaction is subsequently corrected in drift returns (consistent with Rajgopal et al., 2003). Investor overreaction is, however, corrected for firms that disclose OB numbers during their calls; the coefficient on the interaction of $B K L^{*} N U M$ is positive and significant at $10 \%$, with the coefficient estimate of 0.0188 (t-statistics $=1.92$ ). This positive association suggests that firms that support their OB discussions with numbers do not experience investor overreaction to the tone of OB disclosures. Taken together, these results seem to indicate that quantitative disclosures of OB play a role in investors' valuation decisions by correcting investor mispricing of OB tone on earnings calls.

Next, we examine whether these results are robust to using changes of OB tone $\left(C H \_B K L\right)$ as an alternative measure, which removes normal levels of OB discussions by call participants. Table 5 
presents the results of estimating the relationship between $C H \_B K L, N U M, C H \_B K L * N U M$ and market reactions on the conference call day, as well as three months following the call. The coefficients on $C H \_B K L$ are positive and statistically significant at $5 \%$ for Columns [1] and [2], where XRET_PRELIM is the dependent variable. This relation is consistent with our previous findings in Table 3 and suggests that investors recognize increases in the optimism of OB tone disclosures to be a positive signal. Similar to our findings in Table 4, neither NUM or CH_BKL*NUM are significant. However, when XRET_DRIFT is used as a dependent variable in columns [3] and [4], the coefficients on $C H_{-} B K L$ and $C H_{-} B K L * N U M$ are similar to the pattern observed in Table 4 for the $\mathrm{OB}$ tone level $(B K L)$. Investors seem to be overreacting to the changes in OB tone (the coefficient on $C_{-}{ }_{-} B K L$ is negative at -0.0100 ). However, this mispricing is corrected for firms that disclose OB numbers on the call; the interaction of $C H \_B K L * N U M$ is positive (0.0141) and significant at a 10 percent level (t-statistics=1.65). This result supports our previous findings that quantitative $\mathrm{OB}$ disclosures play a role in investor valuations of $\mathrm{OB}$ tone.

\subsection{Usefulness of OB Tone for Make-to-Stock vs. Make-to-Order Firms}

The final set of empirical results explores whether investor reaction to OB tone varies with the relevance of $\mathrm{OB}$ disclosures. We predict that $\mathrm{OB}$ disclosures are more useful for firms with lower levels of Finished Goods Inventory (Make-to-Order firms), since these firms derive more demand from their OB. We predict the opposite for firms that hold significant amounts of their inventory in Finished goods - Make-to-Stock firms. We expect that investors react more (less) strongly to OB tone of Make-to-Order (Make-to-Stock) firms, since OB disclosures are more (less) relevant for these firms.

To separate firms into these two categories, we calculate the proportion of Finished Goods Inventory to the Total Inventory in Compustat for the quarter. We exclude firms without Inventory 
(3,610 observations); if Finished Goods Inventory balance is missing, we set it equal to zero. We assign firms to the Make-to-Stock groups if they are in the top quartile of the Finished Goods proportion (more than 35\% of their total inventory consists of Finished Goods), and the remaining firms are assigned to Make-to-Order group.

Table 6 presents the regression results of immediate market reactions for the two groups of firm calls. The BKL coefficient is insignificant for Make-to-Stock firms (Columns [1] and [2]). However, the coefficient loads positively and significantly for Make-to-Order firms: 0.0066 for Column [3] with t-statistics $=2.85$ and 0.0067 for Column [4] with t-statistics $=2.93$. Table 7 presents the results of subsequent drift returns for the two groups of firm calls. Consistent with our previous findings, $B K L$ is not significant across all specifications.

Overall, the results suggest that investors recognize the value relevance of $\mathrm{OB}$ disclosures only for Make-to-Order firms. They do not consider these discussions particularly important for Make-toStock firms. Our findings for the qualitative quarterly $\mathrm{OB}$ disclosures further confirm results from Toynbee (2018) who finds that annual quantitative OB disclosures are less relevant for Make-toStock firms.

\section{Conclusion}

Certain features of OB disclosures make it difficult to infer its usefulness to investors: it is a selfreported and unaudited disclosure that has no accounting rules. As a result, OB practices and timing of OB disclosures vary across industries, firms and possibly even company segments. Prior accounting literature studied mostly annual (10-K) quantitative OB disclosures and had sparse and inconclusive findings. 
We approach the study of OB usefulness from a different perspective: we focus on OB disclosures in the transcripts of quarterly earnings conference calls. This allows us to, first, pinpoint the exact time when $\mathrm{OB}$ disclosures are released to the market, enabling us to directly investigate the effects of OB on stock returns. Second, since earnings calls are a voluntary form of disclosure, we can assume that our sample consists of firms whose managers or analysts consider OB important information. By the same token, our sample presumably does not include firms that are only disclosing OB information to meet SEC requirements. Finally, the use of NLP technology allows us to study both quantitative and qualitative disclosures of $\mathrm{OB}$ in the language of the earnings calls.

Using commercially available NLP software, we create a set of rules that extract instances of OB mentions and classify them as positive or negative; this allows us to assign a measure of backlog tone to each earnings call that has OB disclosures. We study market reaction to OB tone and find that investors react to this measure and also recognize its direction: we find that a more positive OB tone results in higher abnormal stock returns at the time of the call. This result is robust for both levels and changes of $\mathrm{OB}$ tone, and suggests that investors view more optimistic OB mentions as good news and use them in their valuation decisions. We also find some evidence that firms' qualitative $\mathrm{OB}$ disclosures accompanied by quantitative backlog information temper investor overreaction, as numeric OB disclosures provides a more precise message to investors. Finally, we show that $\mathrm{OB}$ tone is more relevant for Make-to-Order firms that rely more on OB for their future revenue compared to Make-to-Stock firms.

The results of this study are relevant to academics, investors, regulators and firms. The results indicate that $\mathrm{OB}$ tone is positively associated with abnormal stock returns, helping to shed more light on prior academic studies. We show that investors may rely on OB signals disclosed not only in annual filings, but also in quarterly announcements, whether the signal is numeric or qualitative 
in nature. Regulators may consider requiring firms to provide $\mathrm{OB}$ information in quarterly intervals, whether quantitative or qualitative, because this information is beneficial to investors. Regulators might also consider refining their approach to the mandated annual OB disclosures, which might not be relevant to all publicly traded companies. Finally, managers of firms may find it beneficial to provide OB disclosures (quantitatively or qualitatively) in quarterly intervals (or even more frequently), thereby reducing information uncertainty and asymmetry about the firm, and as a consequence, potentially reducing the cost of capital. 


\section{REFERENCES}

Abarbanell, J., and B. Bushee. 1997. Fundamental analysis, future earnings, and stock prices. Journal of Accounting Research 35 (1), 1-24.

Aboody, D., and R. Kasznik. 2000. CEO stock options awards and the timing of corporate voluntary disclosures. Journal of Accounting and Economics 29, 73-100.

Ball, R., Brown, P., 1968. An empirical evaluation of accounting income numbers. Journal of Accounting Research 6, 159-178.

Behn, B.K., 1996, "Value implications of unfilled order backlogs," Advances in Accounting, 14, 61-84.

Bernard, V., Thomas, J., 1989. Post-earnings-announcement drift: delayed price response or risk premium? Journal of Accounting Research 27, 1-36.

Bernard, V., Thomas, J., 1990. Evidence that stock prices do not fully reflect the implications of current earnings for future earnings. Journal of Accounting and Economics 13, 305-340.

Bozanic, Z., D.T. Roulstone, and A. Van Buskirk. 2017. Management Earnings Forecasts and Other Forward-Looking Statements. Journal of Accounting \& Economics, Forthcoming.

Brockman, P., X. Li, S.M. Price. 2015. Differences in Conference Call Tones: Managers versus Analysts. Financial Analyst Journal 71; 24-42.

Daniel, K., M. Grinblatt, S. Titman and R. Wermers. 1997. Measuring Mutual Fund Performance with Characteristic-Based Benchmarks. Journal of Finance 52 (3): 1035-1058.

Fama, E. and J. Macbeth. 1973. Risk, Return and Equilibrium: Empirical Tests. Journal of Political Economy 81, 607-636.

Feldman, R., Govindaraj, J., Livnat, J., Segal, B. 2010. Management's tone change, post earnings announcement drift and accruals. Review of Accounting Studies 15(4) 915-953.

Francis, J., K. Schipper and L. Vincent, 2003, "The relative and incremental information content of alternative to earnings performance measures," Contemporary Accounting Research, 20 (Spring 2003), 121-164.

Gow, I. D., Ormazabal, G. and Taylor, D. J. (2010). Correcting for cross-sectional and timeseries dependence in accounting research. The Accounting Review, 85(2), 483-512.

Graham, J. R., C. R. Harvey, and S. Rajgopal. 2005. The Economic Implications of Corporate Financial Reporting. Journal of Accounting \& Economics 40 (1-3):3-73.

Gu, L., and Huang, D., 2010, Sales order backlogs and Momentum Profits, Journal of Banking and Finance, 34, 1564-1575

Gu L., Z. Wang, and J, Ye. 2008. Information in Order Backlog: Change versus Level. Working Paper Xiamen University, Fujian.

Healy P.M., and G. K. Palepu. 2001. Information asymmetry, corporate disclosure, and the capital markets: A review of the empirical disclosure literature, Journal of Accounting and Economics, 31, (1-3), 405-440. 
Henry, E. 2008. Are Investors Influenced By How Earnings Press Releases Are Written? Journal of Business Communication 45.4.

Lahiri, K. (Editor), and Moore, G.H. (Editor). 1992. Leading Economic Indicators: New Approaches and Forecasting, Cambridge University Press.

Lerman, A., and J. Livnat. 2010. The New Form 8-K Disclosures. Review of Accounting Studies $15,752-778$.

Lev, B., and S. Thiagarajan. 1993. Fundamental Information Analysis. Journal of Accounting Research, 31, 190-215.

Li, F., 2010. The information content of forward-looking statements in corporate filings - A naïve Bayesian machine learning approach. Journal of Accounting Research 48(5), 1049-1102.

Livnat, J., and R. Mendenhall. 2006. Comparing the Post-Earnings Announcement Drift for Surprises Calculated from Analyst and Time Series Forecasts. Journal of Accounting Research, 44, 1, 177-205.

Livnat, J., and N. Jegadeesh. 2006. Post-Earnings-Announcement Drift: The Role of Revenue Surprises. Financial Analyst Journal, 62 (2).

Livnat, J., and S. G. Ryan. 2011. Accessing Inventory Management and Capacity Requirements Using Financial Reports. Bridging the GAAP: Recent Advances in Finance and Accounting, World Scientific Series in Finance: Volume 1. 93-119.

Loughran, T., McDonald, B. 2011. When Is a Liability Not a Liability? Textual Analysis, Dictionaries, and 10-Ks. The Journal of Finance. 66(1) 35-65.

Mishkin, F. (1983). A Rational Expectations Approach to Macroeconometrics: Testing Policy Ineffectiveness and Efficient-Markets Models. Chicago: University of Chicago Press.

Petersen, M. A. (2009). Estimating standard errors in finance panel data sets: Comparing approaches. Review of Financial Studies, 22(1), 435-480.

Price, S. M., J. S. Doran, D. R. Peterson, and B. A. Bliss. 2012. Earnings Conference Calls and Stock Returns: The Incremental Informativeness of Textual Tone. Journal of Banking \& Finance, 36, pp. 992-1011.

Rajgopal, S., T. Shevlin, and M. Venkatachalam. 2003. Does the Stock Market Fully Appreciate the Implications of Leading Indicators for Future Earnings? Evidence from Order Backlog. Review of Accounting Studies, 8, 461-492.

Silhan, P. A., and T. J. Frecka. 1986. On the Sales Forecasting Benefits of Form 10-K Backlog Information. Journal of Business Finance \& Accounting, 13(3), 425-431.

Sloan, R. G. 1996. Do Stock Prices Fully Reflect Information in Accruals and Cash Flows About Future Earnings? The Accounting Review 71, 3: 289-315.

Suijs, J. 2005. Voluntary Disclosure of Bad News. Journal of Business Finance \& Accounting, 32: $1423-1435$.

Sun, Y. 2010. Do MD\&A Disclosures Help Users Interpret Disproportionate Inventory Increases? The Accounting Review, Vol. 85, No. 4, 1411-1440. 
Thomas, J. K., and H. Zhang. 2002. Inventory changes and future returns. Review of Accounting Studies 7, 2-3: 163-187.

Toynbee, S. 2018. Implications of Disclosing Order Backlog. Working Paper. University of Texas at Austin.

Xuejun Li, Edward, and K. Ramesh. 2009. Market Reaction Surrounding the Filing of Periodic SEC Reports. The Accounting Review 84, 4: 1171-1208. 


\section{Appendix 1: Variable Definitions}

$B K L$

CH_BKL

$N U M$

TONE

CH_TONE

SUEAFl

SUEAF2

STD_EARN

$B M$

ASSETS

MKT

MAKE-TOSTOCK FIRMS

MAKE-TOORDER FIRMS
The total number of positive OB mentions less the total number of negative OB mentions in a conference call divided by the total number of $\mathrm{OB}$ mentions (positive plus negative and plus neutral). For regression analysis, $B K L$ is normalized between -0.5 and 0.5 by ranking it into quartiles ( 0 to 3 ) each fiscal quarter, dividing the rank by 3 and subtracting 0.5 .

The difference between the $B K L$ in a company's conference call and the mean $B K L$ in the company's conference calls held within the preceding 370 calendar days. For regression analysis $C H \_B K L$ is normalized between -0.5 and 0.5 by ranking it into quartiles ( 0 to 3 ) each fiscal quarter, dividing the rank by 3 and subtracting 0.5 .

A dummy variable equal to 1 if backlog discussions mention the dollar amount of backlog and zero otherwise.

The measure of sentiment based on the number of positive minus the number of negative words in a conference call, scaled by the sum of the positive and the negative words; the list of positive and negative words is based on the Loughran and McDonald (2011) and extended Amenity dictionary. For regression analysis TONE is normalized between -0.5 and 0.5 by ranking it into deciles ( 0 to 9 ) each fiscal quarter, dividing the rank by 9 , and subtracting 0.5 .

The difference between the TONE in a company's conference call and the mean TONE in the company's conference calls held within the preceding 370 calendar days. For regression analysis $\mathrm{CH}_{-} \mathrm{TONE}$ is normalized between -0.5 and 0.5 by ranking it into deciles ( 0 to 9 ) each fiscal quarter, dividing the rank by 9 , and subtracting 0.5 .

The difference between the actual earnings reported per IBES and the mean earnings preliminary estimate, divided by the standard deviation of the earnings forecasts. All forecasts made in thee 90-day period prior to the earnings announcement are used to calculate the mean and standard deviation, with only the most recent forecast for each analyst. For regression analysis SUEAF1 is normalized between -0.5 and 0.5 by ranking it into deciles $(0$ to 9 ) each fiscal quarter, dividing the rank by 9 , and subtracting 0.5 .

The difference between the actual earnings reported per IBES and the mean earnings preliminary estimate, divided by the price at month-end prior to the earnings announcement date. For regression analysis SUEAF2 is normalized between -0.5 and 0.5 by ranking it into deciles ( 0 to 9 ) each fiscal quarter, dividing the rank by 9 , and subtracting 0.5 .

The standard deviation of analysts' earnings forecasts for the quarter that are made during the 90-day period prior to the quarter's earnings announcement. Only the most recent analyst forecast is used to calculate the standard deviation.

Shareholder's equity from the prior quarter divided by market value at the end of the month prior to the earnings announcement.

The total assets at the end of the prior quarter.

The market value of equity at the end of the month prior to the earnings announcement.

We rank all firms on the proportion of total inventory held as Finished Goods, and classify firms as Make-to-Stock if they belong to the top quartile of this measurement (highest proportion of total inventory held as Finished Goods).

We rank all firms on the proportion of total inventory held as Finished Goods, and classify firms as Make-to-Order if they do not belong to the top quartile of this measurement (highest proportion of total inventory held as Finished Goods). 
XRET_PRELIM The buy-and-hold return on a stock minus the value-weighted buy-and hold return on a matched size-B/ M-momentum portfolio in the interval $[-1,+1]$, where day 0 is the preliminary earnings announcement date. For regression analysis when XRET_PRELIM is used as an independent variable, it is normalized between -0.5 and 0.5 by ranking it into deciles ( 0 to 9 ) each fiscal quarter, dividing the rank by 9 , and subtracting 0.5 .

XRET_DRIFT The buy-and-hold return on a stock minus the average return on a matched size-B/Mmomentum portfolio from two days after the preliminary earnings announcement date through one day after the subsequent quarter's preliminary earnings announcement. 
Figure 1 Backlog Disclosures in the Earnings Calls

Figure 1A shows the number of companies with conference calls and those that discuss $\mathrm{OB}$ on their earnings calls. Figure 1B plots the proportion of calls with $\mathrm{OB}$ disclosures for the sample time period.

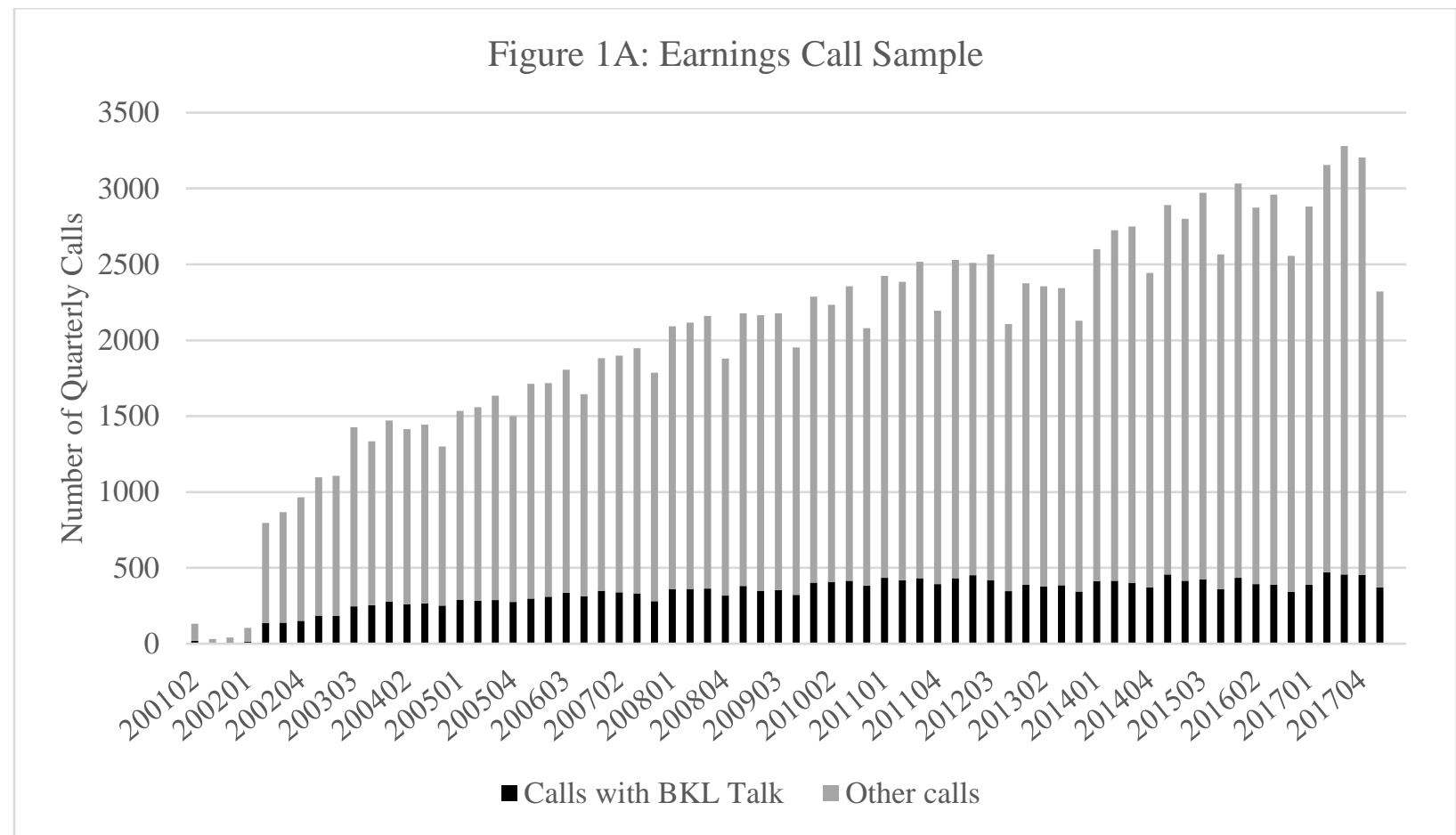

Sources: Thomson Reuters, I/B/E/S, Amenity Analytics, QMA. As of 3/15/2020.

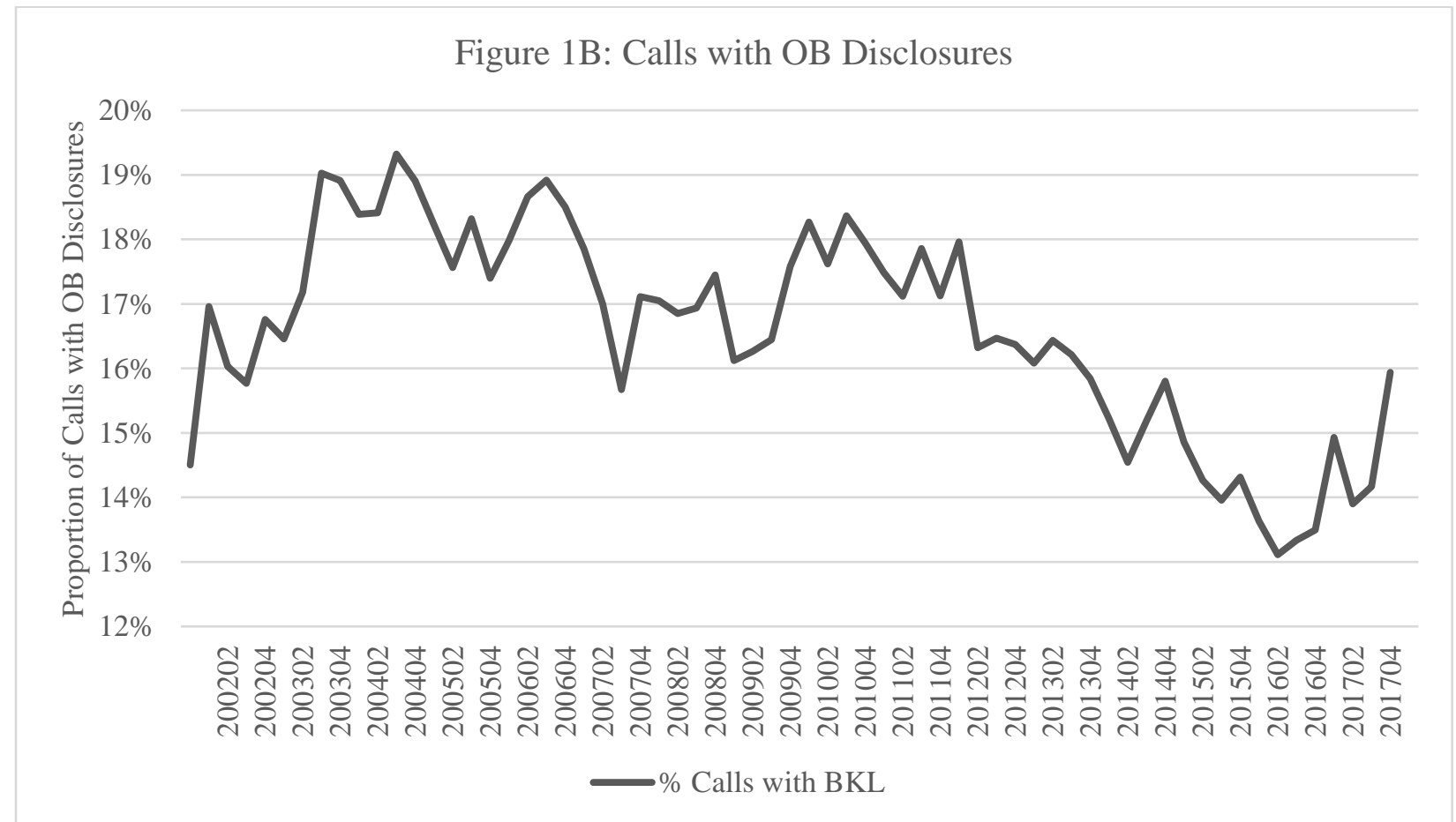

Sources: Thomson Reuters, I/B/E/S, Amenity Analytics, QMA. As of 3/15/2020. 
Table 1: Summary Statistics and Correlations

This table reports summary statistics for variables used in the paper. Panel A reports the summary statistics for the variables used in the analysis. Panel B reports the Spearman correlation between the variables (boldface represents a significance level of 0.01). The sample consists of all US firms in Thompson Reuter's conference calls database for the years 2002-2018. Individual variable definitions are outlined in Appendix 1.

Panel A: Summary Statistics

\begin{tabular}{lcccccccc}
\hline \multicolumn{1}{c}{ Variable } & N & Mean & Std Dev & P1 & P25 & Median & P75 & P99 \\
\hline BKL & 22,426 & 0.57 & 0.60 & -1.00 & 0.25 & 1.00 & 1.00 & 1.00 \\
CH_BKL & 17,998 & -0.01 & 0.64 & -2.00 & -0.25 & 0.00 & 0.29 & 2.00 \\
NUM & 22,426 & 0.54 & 0.50 & 0.00 & 0.00 & 1.00 & 1.00 & 1.00 \\
TONE & 22,426 & 0.37 & 0.24 & -0.26 & 0.21 & 0.39 & 0.55 & 0.82 \\
CH_TONE & 17,998 & 0.01 & 0.20 & -0.53 & -0.12 & 0.01 & 0.14 & 0.48 \\
SUEAF1 & 22,426 & -1.97 & 8.74 & -20.00 & -2.00 & 0.39 & 2.04 & 20.00 \\
SUEAF2 & 22,426 & -0.02 & 0.05 & -0.12 & 0.00 & 0.00 & 0.00 & 0.06 \\
STD_EARN & 22,426 & 0.04 & 0.08 & 0.01 & 0.01 & 0.01 & 0.04 & 0.59 \\
ASSETS & 22,426 & 12450.62 & 87091.71 & 21.45 & 388.27 & 1236.10 & 3878.23 & 146188.69 \\
MKT & 22,426 & 6406.27 & 23581.24 & 23.59 & 392.37 & 1213.50 & 3734.89 & 98750.11 \\
BM & 22,426 & 0.53 & 0.71 & -0.32 & 0.29 & 0.46 & 0.69 & 2.20 \\
XRET_PRELIM & 22,426 & 0.00 & 0.09 & -0.24 & -0.04 & 0.00 & 0.05 & 0.23 \\
XRET_DRIFT & 22,426 & 0.00 & 0.19 & -0.46 & -0.10 & 0.00 & 0.09 & 0.56 \\
\hline
\end{tabular}

Panel B: Spearman Correlations

\begin{tabular}{lcccccccccc}
\hline & 1 & 2 & 3 & 4 & 5 & 6 & 7 & 8 & 9 & 10 \\
\hline 1. BKL & 1.00 & & & & & & & & & \\
2. CH_BKL & $\mathbf{0 . 6 4}$ & 1.00 & & & & & & & & \\
3. TONE & $\mathbf{0 . 2 2}$ & $\mathbf{0 . 0 9}$ & 1.00 & & & & & & & \\
4. CH_TONE & $\mathbf{0 . 1 2}$ & $\mathbf{0 . 1 7}$ & $\mathbf{0 . 5 6}$ & 1.00 & & & & & & \\
5. SUEAF1 & $\mathbf{0 . 0 3}$ & 0.00 & $\mathbf{0 . 2 7}$ & $\mathbf{0 . 2 2}$ & 1.00 & & & & & \\
6. SUEAF2 & 0.00 & -0.02 & $\mathbf{0 . 2 0}$ & $\mathbf{0 . 2 1}$ & $\mathbf{0 . 8 9}$ & 1.00 & & & & \\
7. STD_EARN & $\mathbf{- 0 . 0 4}$ & -0.01 & $\mathbf{- 0 . 1 3}$ & $\mathbf{- 0 . 0 4}$ & $\mathbf{- 0 . 1 5}$ & 0.01 & 1.00 & & & \\
8. ASSETS & $\mathbf{0 . 0 5}$ & 0.01 & $\mathbf{- 0 . 0 5}$ & -0.01 & $\mathbf{0 . 0 7}$ & 0.01 & $\mathbf{0 . 3 6}$ & 1.00 & & \\
9. BM & $\mathbf{- 0 . 0 9}$ & $\mathbf{- 0 . 0 2}$ & $\mathbf{- 0 . 2 7}$ & -0.01 & $\mathbf{- 0 . 0 5}$ & $\mathbf{0 . 0 6}$ & $\mathbf{0 . 0 4}$ & $\mathbf{- 0 . 0 4}$ & 1.00 & \\
10. XRET_PRELIM & $\mathbf{0 . 0 6}$ & $\mathbf{0 . 0 6}$ & $\mathbf{0 . 2 4}$ & $\mathbf{0 . 2 6}$ & $\mathbf{0 . 3 7}$ & $\mathbf{0 . 3 6}$ & $\mathbf{- 0 . 0 2}$ & 0.00 & 0.00 & 1.00 \\
11. XRET_DRIFT & $\mathbf{0 . 0 2}$ & 0.01 & $\mathbf{0 . 0 5}$ & $\mathbf{0 . 0 7}$ & $\mathbf{0 . 0 2}$ & 0.01 & $\mathbf{- 0 . 0 4}$ & 0.02 & 0.01 & $\mathbf{0 . 0 3}$ \\
\hline
\end{tabular}

Sources: Thomson Reuters, Compustat, I/B/E/S, CSRP, Amenity Analytics, QMA. As of 3/15/2020. 
Table 2: Investor Reactions to Backlog Disclosures

The table reports the results of the panel regression of the immediate and drift excess buy-and-hold returns on $B K L$ and other control variables. The dependent variable in columns [1] and [2] (XRET_PRELIM) is the buy-and-hold return on a stock minus the value weighted return on a matched size-B/ M-momentum portfolio in the interval [-1, +1 ], where day 0 is the preliminary earnings announcement date. The dependent variable in columns [3] and [4] (XRET_DRIFT) is the buy-and-hold return on a stock minus the value weighted return on a matched size-B/Mmomentum portfolio from two days after the preliminary earnings announcement date through one day after the subsequent quarter's preliminary earnings announcement. Individual variable definitions are outlined in Appendix 1. Standard errors are clustered by firm and time (year-quarter) following Petersen (2009) and Gow et al. (2010). Robust $\mathrm{t}$-statistics are reported in parenthesis. Significance level: $* * * \mathrm{p}<0.01, * * \mathrm{p}<0.05,{ }^{*} \mathrm{p}<0.1$.

\begin{tabular}{|c|c|c|c|c|}
\hline \multirow[t]{2}{*}{ Variables } & \multicolumn{2}{|c|}{ Dependent Variable $=X R E T \_P R E L I M$} & \multicolumn{2}{|c|}{ Dependent Variable $=$ XRET_DRIFT } \\
\hline & [1] & [2] & [3] & [4] \\
\hline Intercept & $\begin{array}{c}0.0135 * * * \\
(3.78)\end{array}$ & $\begin{array}{c}0.0077 * * \\
(2.11)\end{array}$ & $\begin{array}{c}0.0118 \\
(1.06)\end{array}$ & $\begin{array}{l}0.0115 \\
(1.04)\end{array}$ \\
\hline$B K L$ & $\begin{array}{c}0.0085^{* * * *} \\
(3.84)\end{array}$ & $\begin{array}{c}0.0089 * * * \\
(3.97)\end{array}$ & $\begin{array}{c}-0.0026 \\
(-0.56)\end{array}$ & $\begin{array}{c}-0.0027 \\
(-0.58)\end{array}$ \\
\hline TONE & $\begin{array}{c}0.0399 * * * \\
(16.70)\end{array}$ & $\begin{array}{c}0.0433 * * * \\
(18.08)\end{array}$ & $\begin{array}{c}0.0177 * * * \\
(2.98)\end{array}$ & $\begin{array}{c}0.0180 * * * \\
(3.01)\end{array}$ \\
\hline SUEAF1 & $\begin{array}{c}0.0848 * * * \\
(25.95)\end{array}$ & & $\begin{array}{c}0.0031 \\
(0.54)\end{array}$ & \\
\hline SUEAF2 & & $\begin{array}{c}0.0842 * * * \\
(27.24)\end{array}$ & & $\begin{array}{c}0.0019 \\
(0.33)\end{array}$ \\
\hline $\log (A S S E T S)$ & $\begin{array}{c}-0.0016 * * * \\
(-3.65)\end{array}$ & $\begin{array}{c}-0.0005 \\
(-1.01)\end{array}$ & $\begin{array}{c}-0.0005 \\
(-0.37)\end{array}$ & $\begin{array}{c}-0.0004 \\
(-0.34)\end{array}$ \\
\hline$B M$ & $\begin{array}{c}0.0020 \\
(0.65)\end{array}$ & $\begin{array}{c}0.0003 \\
(0.11)\end{array}$ & $\begin{array}{l}-0.0011 \\
(-0.19)\end{array}$ & $\begin{array}{l}-0.0011 \\
(-0.20)\end{array}$ \\
\hline$S T D \_E A R N$ & $\begin{array}{c}0.0377 * * * \\
(4.02)\end{array}$ & $\begin{array}{c}0.0113 \\
(0.15)\end{array}$ & $\begin{array}{c}-0.0731 * * \\
(-2.35)\end{array}$ & $\begin{array}{c}-0.0744 * * \\
(-2.38)\end{array}$ \\
\hline XRET_PRELIM & & & $\begin{array}{l}0.0044 \\
(0.76)\end{array}$ & $\begin{array}{l}0.0048 \\
(0.84)\end{array}$ \\
\hline $\begin{array}{l}\text { No. Obs. } \\
\text { R-squared }\end{array}$ & $\begin{array}{l}22,426 \\
1079 \%\end{array}$ & $\begin{array}{l}22,426 \\
11,04 \%\end{array}$ & $\begin{array}{l}22,426 \\
0,34 \%\end{array}$ & $\begin{array}{l}22,426 \\
0,34 \%\end{array}$ \\
\hline
\end{tabular}

Sources: Thomson Reuters, Compustat, I/B/E/S, CSRP, Amenity Analytics, QMA. As of 3/15/2020. 
Table 3: Investor Reactions to the Changes in Backlog Disclosures

The table reports the results of the panel regression of the immediate excess buy-and-hold returns on $C H \_B K L$ and other control variables. The dependent variable in columns [1] and [2] (XRET_PRELIM) is the buy-and-hold return on a stock minus the value weighted return on a matched size-B/ M-momentum portfolio in the interval [-1, +1], where day 0 is the preliminary earnings announcement date. The dependent variable in columns [3] and [4] (XRET_DRIFT) is the buy-and-hold return on a stock minus the value weighted return on a matched size-B/M-momentum portfolio from two days after the preliminary earnings announcement date through one day after the subsequent quarter's preliminary earnings announcement. Individual variable definitions are outlined in Appendix 1. Standard errors are clustered by firm and time (year-quarter) following Petersen (2009) and Gow et al. (2010). Robust t-statistics are reported in parenthesis. Significance level: $* * * \mathrm{p}<0.01, * * \mathrm{p}<0.05, * \mathrm{p}<0.1$.

\begin{tabular}{|c|c|c|c|c|}
\hline \multirow[t]{2}{*}{ Variables } & \multicolumn{2}{|c|}{ Dependent Variable $=X R E T \_P R E L I M$} & \multicolumn{2}{|c|}{ Dependent Variable $=X R E T \_D R I F T$} \\
\hline & [1] & [2] & [3] & [4] \\
\hline Intercept & $\begin{array}{c}0.0195^{* * *} * \\
(5.66)\end{array}$ & $\begin{array}{c}0.0137 * * * \\
(3.75)\end{array}$ & $\begin{array}{c}0.0136 \\
(1.34)\end{array}$ & $\begin{array}{c}0.0135 \\
(1.35)\end{array}$ \\
\hline$C H \_B K L$ & $\begin{array}{c}0.0072 * * * \\
(3.87)\end{array}$ & $\begin{array}{c}0.0078^{* * * *} \\
(4.06)\end{array}$ & $\begin{array}{c}-0.0007 \\
(-0.20)\end{array}$ & $\begin{array}{c}-0.0009 \\
(-0.25)\end{array}$ \\
\hline CH_TONE & $\begin{array}{c}0.0534 * * * \\
(18.51)\end{array}$ & $\begin{array}{c}0.0544 * * * \\
(19.26)\end{array}$ & $\begin{array}{c}0.0340 * * * \\
(4.91)\end{array}$ & $\begin{array}{c}0.0340 * * * \\
(4.95)\end{array}$ \\
\hline SUEAF1 & $\begin{array}{c}0.0835 * * * \\
(24.86)\end{array}$ & & $\begin{array}{c}-0.0004 \\
(-0.07)\end{array}$ & \\
\hline$S U E A F 2$ & & $\begin{array}{c}0.0816 * * * \\
(24.77)\end{array}$ & & $\begin{array}{c}-0.0040 \\
(-0.66)\end{array}$ \\
\hline $\log (A S S E T S)$ & $\begin{array}{c}-0.0021 * * * \\
(-4.97)\end{array}$ & $\begin{array}{c}-0.0010 * * \\
(-2.13)\end{array}$ & $\begin{array}{c}-0.0006 \\
(-0.56)\end{array}$ & $\begin{array}{c}-0.0006 \\
(-0.55)\end{array}$ \\
\hline$B M$ & $\begin{array}{c}-0.0006 \\
(-0.26)\end{array}$ & $\begin{array}{l}-0.0024 \\
(-1.17)\end{array}$ & $\begin{array}{c}-0.0036 \\
(-0.56)\end{array}$ & $\begin{array}{c}-0.0036 \\
(-0.55)\end{array}$ \\
\hline$S T D \_E A R N$ & $\begin{array}{c}0.0204^{*} \\
(1.95)\end{array}$ & $\begin{array}{c}-0.0182^{*} \\
(-1.87)\end{array}$ & $\begin{array}{c}-0.0635^{* *} \\
(-2.05)\end{array}$ & $\begin{array}{c}-0.0636 * * \\
(-2.03)\end{array}$ \\
\hline XRET_PRELIM & & & $\begin{array}{c}-0.0051 \\
(-0.84)\end{array}$ & $\begin{array}{c}-0.0040 \\
(-0.66)\end{array}$ \\
\hline No. Obs. & 17,998 & 17,998 & 17,998 & 17,998 \\
\hline R-squared & $16.71 \%$ & $16.53 \%$ & $0.45 \%$ & $0.45 \%$ \\
\hline
\end{tabular}

Sources: Thomson Reuters, Compustat, I/B/E/S, CSRP, Amenity Analytics, QMA. As of 3/15/2020. 
Table 4: Investor Reactions to Backlog Disclosures with OB Numbers

The table reports the results of the panel regression of the excess buy-and-hold returns on $N U M, B K L, B K L * N U M$, and other control variables. The dependent variable in columns [1] and [2] (XRET_PRELIM) is the buy-and-hold return on a stock minus the value weighted return on a matched size-B/ M-momentum portfolio in the interval [-1, +1 , where day 0 is the preliminary earnings announcement date. The dependent variable in columns [3] and [4] (XRET_DRIFT) is the buy-and-hold return on a stock minus the value weighted return on a matched size-B/Mmomentum portfolio from two days after the preliminary earnings announcement date through one day after the subsequent quarter's preliminary earnings announcement. Individual variable definitions are outlined in Appendix 1. Standard errors are clustered by firm and time (year-quarter) following Petersen (2009) and Gow et al. (2010). Robust $\mathrm{t}$-statistics are reported in parenthesis. Significance level: *** $\mathrm{p}<0.01, * * \mathrm{p}<0.05, * \mathrm{p}<0.1$.

\begin{tabular}{|c|c|c|c|c|}
\hline \multirow[t]{2}{*}{ Variables } & \multicolumn{2}{|c|}{ Dependent Variable $=X R E T \_P R E L I M$} & \multicolumn{2}{|c|}{ Dependent Variable $=$ XRET_DRIFT } \\
\hline & [1] & [2] & [3] & [4] \\
\hline Intercept & $\begin{array}{c}0.0136 * * * \\
(3.71)\end{array}$ & $\begin{array}{c}0.0075^{* *} \\
(2.01)\end{array}$ & $\begin{array}{c}0.0152 \\
(1.32)\end{array}$ & $\begin{array}{c}0.0149 \\
(1.30)\end{array}$ \\
\hline$B K L$ & $\begin{array}{c}0.0065^{* *} \\
(2.07)\end{array}$ & $\begin{array}{c}0.0067 * * \\
(2.05)\end{array}$ & $\begin{array}{c}-0.0153 * * \\
(-2.03)\end{array}$ & $\begin{array}{c}-0.0154 * * \\
(-2.03)\end{array}$ \\
\hline NUM & $\begin{array}{c}0.0007 \\
(0.52)\end{array}$ & $\begin{array}{c}0.0011 \\
(0.87)\end{array}$ & $\begin{array}{c}-0.0032 \\
(-0.98)\end{array}$ & $\begin{array}{c}-0.0032 \\
(-0.98)\end{array}$ \\
\hline$B K L * N U M$ & $\begin{array}{c}0.0044 \\
(1.24)\end{array}$ & $\begin{array}{c}0.0053 \\
(1.46)\end{array}$ & $\begin{array}{c}0.0188 * \\
(1.92)\end{array}$ & $\begin{array}{c}0.0188 * \\
(1.91)\end{array}$ \\
\hline TONE & $\begin{array}{c}0.0398 * * * \\
(16.85)\end{array}$ & $\begin{array}{c}0.0431 * * * \\
(18.22)\end{array}$ & $\begin{array}{c}0.0180 * * * \\
(3.07)\end{array}$ & $\begin{array}{c}0.0183 * * * \\
(3.10)\end{array}$ \\
\hline SUEAF1 & $\begin{array}{c}0.0848 * * * \\
(25.98)\end{array}$ & & $\begin{array}{c}0.0031 \\
(0.55)\end{array}$ & \\
\hline$S U E A F 2$ & & $\begin{array}{c}0.0843 * * * \\
(27.29)\end{array}$ & & $\begin{array}{c}0.0019 \\
(0.33)\end{array}$ \\
\hline $\log (A S S E T S)$ & $\begin{array}{c}-0.0016 * * * \\
(-3.70)\end{array}$ & $\begin{array}{c}-0.0005 \\
(-1.05)\end{array}$ & $\begin{array}{c}-0.0006 \\
(-0.46)\end{array}$ & $\begin{array}{c}-0.0005 \\
(-0.43)\end{array}$ \\
\hline$B M$ & $\begin{array}{c}0.0020 \\
(0.66)\end{array}$ & $\begin{array}{c}0.0003 \\
(0.12)\end{array}$ & $\begin{array}{c}-0.0009 \\
(-0.16)\end{array}$ & $\begin{array}{c}-0.0009 \\
(-0.16)\end{array}$ \\
\hline$S T D \_E A R N$ & $\begin{array}{c}0.0378 * * * \\
(4.02)\end{array}$ & $\begin{array}{c}0.0114 \\
(0.16)\end{array}$ & $\begin{array}{c}-0.0727 * * \\
(-2.35)\end{array}$ & $\begin{array}{c}-0.0741 * * \\
(-2.38)\end{array}$ \\
\hline XRET_PRELIM & & & $\begin{array}{l}0.0044 \\
(0.75)\end{array}$ & $\begin{array}{c}0.0048 \\
(0.84)\end{array}$ \\
\hline No. Obs. & 22,426 & 22,426 & 22,426 & 22,426 \\
\hline R-squared & $10.80 \%$ & $11.04 \%$ & $0.46 \%$ & $0.35 \%$ \\
\hline
\end{tabular}

Sources: Thomson Reuters, Compustat, I/B/E/S, CSRP, Amenity Analytics, QMA. As of 3/15/2020. 
Table 5: Investor Reactions to the Changes in Backlog Disclosures with OB Numbers

The table reports the results of the panel regression of the excess buy-and-hold returns on $N U M$, $C H \_B K L$, CH_BKL*NUM, and other control variables. The dependent variable in columns [1] and [2] (XRET_PRELIM) is the buy-and-hold return on a stock minus the value weighted return on a matched size-B/M-momentum portfolio in the interval $[-1,+1]$, where day 0 is the preliminary earnings announcement date. The dependent variable in columns [3] and [4] (XRET_DRIFT) is the buy-and-hold return on a stock minus the value weighted return on a matched size-B/Mmomentum portfolio from two days after the preliminary earnings announcement date through one day after the subsequent quarter's preliminary earnings announcement. Individual variable definitions are outlined in Appendix 1. Standard errors are clustered by firm and time (year-quarter) following Petersen (2009) and Gow et al. (2010). Robust $\mathrm{t}$-statistics are reported in parenthesis. Significance level: $* * * \mathrm{p}<0.01, * * \mathrm{p}<0.05, * \mathrm{p}<0.1$.

\begin{tabular}{|c|c|c|c|c|}
\hline \multirow[t]{2}{*}{ Variables } & \multicolumn{2}{|c|}{ Dependent Variable $=$ XRET_PRELIM } & \multicolumn{2}{|c|}{ Dependent Variable $=$ XRET_DRIFT } \\
\hline & {$[1]$} & [2] & [3] & [4] \\
\hline Intercept & $\begin{array}{c}0.0201 * * * \\
(5.42)\end{array}$ & $\begin{array}{c}0.0140 * * * \\
(4.21)\end{array}$ & $\begin{array}{c}0.0144 \\
(1.34)\end{array}$ & $\begin{array}{c}0.0143 \\
(1.34)\end{array}$ \\
\hline CH_BKL & $\begin{array}{c}0.0064 * * * \\
(2.44)\end{array}$ & $\begin{array}{c}0.0066^{* *} \\
(2.32)\end{array}$ & $\begin{array}{c}-0.0100 \\
(-1.44)\end{array}$ & $\begin{array}{l}-0.0100 \\
(-1.46)\end{array}$ \\
\hline NUM & $\begin{array}{c}-0.0008 \\
(-0.69)\end{array}$ & $\begin{array}{c}-0.0005 \\
(-0.40)\end{array}$ & $\begin{array}{c}-0.0010 \\
(-0.30)\end{array}$ & $\begin{array}{l}-0.0010 \\
(-0.31)\end{array}$ \\
\hline$C H \_B K L * N U M$ & $\begin{array}{l}0.0011 \\
(0.34)\end{array}$ & $\begin{array}{c}0.0018 \\
(0.50)\end{array}$ & $\begin{array}{c}0.0141^{*} \\
(1.65)\end{array}$ & $\begin{array}{c}0.0139 * \\
(1.64)\end{array}$ \\
\hline CH_TONE & $\begin{array}{c}0.0534 * * * \\
(18.52)\end{array}$ & $\begin{array}{c}0.0544 * * * \\
(26.21)\end{array}$ & $\begin{array}{c}0.0339 * * * \\
(4.91)\end{array}$ & $\begin{array}{c}0.0344 * * * * \\
(4.95)\end{array}$ \\
\hline SUEAF1 & $\begin{array}{c}0.0835^{* * * *} \\
(24.88)\end{array}$ & & $\begin{array}{c}-0.0002 \\
(-0.04)\end{array}$ & \\
\hline SUEAF2 & & $\begin{array}{c}0.0816 * * * \\
(35.98)\end{array}$ & & $\begin{array}{c}-0.0038 \\
(-0.63)\end{array}$ \\
\hline $\log (A S S E T S)$ & $\begin{array}{c}-0.0021 * * * \\
(-4.95)\end{array}$ & $\begin{array}{c}-0.0009 * * * \\
(-2.64)\end{array}$ & $\begin{array}{l}-0.0007 \\
(-0.57)\end{array}$ & $\begin{array}{c}-0.0006 \\
(-0.57)\end{array}$ \\
\hline$B M$ & $\begin{array}{l}-0.0006 \\
(-0.25)\end{array}$ & $\begin{array}{c}-0.0023 \\
(-1.16)\end{array}$ & $\begin{array}{c}-0.0035 \\
(-0.55)\end{array}$ & $\begin{array}{l}-0.0035 \\
(-0.54)\end{array}$ \\
\hline$S T D \_E A R N$ & $\begin{array}{c}0.0205^{*} \\
(1.96)\end{array}$ & $\begin{array}{c}-0.0181 * * \\
(-2.12)\end{array}$ & $\begin{array}{c}-0.0632 * * \\
(-2.03)\end{array}$ & $\begin{array}{c}-0.0634 * * \\
(-2.02)\end{array}$ \\
\hline XRET_PRELIM & & & $\begin{array}{c}-0.0051 \\
(0.85)\end{array}$ & $\begin{array}{c}-0.0040 \\
(-0.66)\end{array}$ \\
\hline No. Obs. & 17,998 & 17,998 & 17,998 & 17,998 \\
\hline R-squared & $16.71 \%$ & $16.53 \%$ & $0.46 \%$ & $0.47 \%$ \\
\hline
\end{tabular}

Sources: Thomson Reuters, Compustat, I/B/E/S, CSRP, Amenity Analytics, QMA. As of 3/15/2020. 
Table 6: Immediate Investor Reactions to OB Tone for Make-to-Stock vs. Make-to-Order Firms

The table reports the results of the panel regression of the immediate excess buy-and-hold returns on $B K L$ for the two groups of firms - Make-to-Stock and Make-to-Order. We rank all firms on the proportion of total inventory held as Finished Goods, and classify firms as Make-to-Stock if they belong to the top quartile of this measurement (highest proportion of total inventory held as Finished Goods). The remaining firms are ranked as Make-to-Order firms. The dependent variable (XRET_PRELIM) is the buy-and-hold return on a stock minus the value weighted return on a matched size-B/ M-momentum portfolio in the interval $[-1,+1]$, where day 0 is the preliminary earnings announcement date. Individual variable definitions are outlined in Appendix 1. Standard errors are clustered by firm and time (yearquarter) following Petersen (2009) and Gow et al. (2010). Robust t-statistics are reported in parenthesis. Significance level: *** $\mathrm{p}<0.01, * * \mathrm{p}<0.05, * \mathrm{p}<0.1$.

\begin{tabular}{|c|c|c|c|c|}
\hline \multirow[t]{3}{*}{ Variables } & \multicolumn{4}{|c|}{ Dependent Variable $=X R E T \_P R E L I M$} \\
\hline & \multicolumn{2}{|c|}{ Make-to-Stock Firms } & \multicolumn{2}{|c|}{ Make-to-Order Firms } \\
\hline & {$[1]$} & {$[2]$} & {$[3]$} & {$[4]$} \\
\hline Intercept & $\begin{array}{c}0.0196 * * * \\
(2.79)\end{array}$ & $\begin{array}{c}0.0144 * * \\
(2.09)\end{array}$ & $\begin{array}{c}0.0146 * * * \\
(3.79)\end{array}$ & $\begin{array}{c}0.0123 * * * \\
(3.25)\end{array}$ \\
\hline$B K L$ & $\begin{array}{c}0.0056 \\
(1.25)\end{array}$ & $\begin{array}{c}0.0056 \\
(1.26)\end{array}$ & $\begin{array}{c}0.0066^{* * *} * \\
(2.85)\end{array}$ & $\begin{array}{c}0.0067 * * * \\
(2.93)\end{array}$ \\
\hline TONE & $\begin{array}{c}0.0525 * * * \\
(11.51)\end{array}$ & $\begin{array}{c}0.0542 * * * \\
(12.36)\end{array}$ & $\begin{array}{c}0.0505^{* * *} * \\
(16.05)\end{array}$ & $\begin{array}{c}0.0522 * * * \\
(16.43)\end{array}$ \\
\hline SUEAF1 & $\begin{array}{c}0.0766 * * * \\
(14.51)\end{array}$ & & $\begin{array}{c}0.0623 * * * \\
(17.73)\end{array}$ & \\
\hline$S U E A F 2$ & & $\begin{array}{c}0.0822 * * * \\
(13.76)\end{array}$ & & $\begin{array}{c}0.0612 * * * \\
(18.61)\end{array}$ \\
\hline $\log (A S S E T S)$ & $\begin{array}{c}-0.0021 * * \\
(-2.42)\end{array}$ & $\begin{array}{c}-0.0011 \\
(-1.23)\end{array}$ & $\begin{array}{c}-0.0021 * * * \\
(-4.27)\end{array}$ & $\begin{array}{c}-0.0016 * * * \\
(-3.41)\end{array}$ \\
\hline$B M$ & $\begin{array}{c}-0.0028 \\
(-0.57)\end{array}$ & $\begin{array}{c}-0.0038 \\
(-0.86)\end{array}$ & $\begin{array}{c}0.0077 \\
(2.97)\end{array}$ & $\begin{array}{c}0.0064 \\
(2.69)\end{array}$ \\
\hline$S T D \_E A R N$ & $\begin{array}{c}-0.0447 \\
(-1.53)\end{array}$ & $\begin{array}{c}-0.0774 * * * \\
(-3.16)\end{array}$ & $\begin{array}{c}0.0099 \\
(0.95)\end{array}$ & $\begin{array}{c}-0.0062 \\
(-0.59)\end{array}$ \\
\hline $\begin{array}{l}\text { No. Obs. } \\
\text { R-squared }\end{array}$ & $\begin{array}{c}4,829 \\
13.34 \% \\
\end{array}$ & $\begin{array}{c}4,829 \\
14.10 \% \\
\end{array}$ & $\begin{array}{r}13,987 \\
10.39 \% \\
\end{array}$ & $\begin{array}{c}13,987 \\
10.49 \% \\
\end{array}$ \\
\hline
\end{tabular}

Sources: Thomson Reuters, Compustat, I/B/E/S, CSRP, Amenity Analytics, QMA. As of 3/15/2020. 
Table 7: Subsequent Investor Reactions to OB Tone for Make-to-Stock vs. Make-to-Order Firms

The table reports the results of the panel regression of the drift excess buy-and-hold returns on $B K L$ for the two groups of firms - Make-to-Stock and Make-to-Order. We rank all firms on the proportion of total inventory held as Finished Goods, and classify firms as Make-to-Stock if they belong to the top quartile of this measurement (highest proportion of total inventory held as Finished Goods). The remaining firms are ranked as Make-to-Order firms. The dependent variable (XRET_DRIFT) is the buy-and-hold return on a stock minus the value weighted return on a matched sizeB/M-momentum portfolio from two days after the preliminary earnings announcement date through one day after the subsequent quarter's preliminary earnings announcement. Individual variable definitions are outlined in Appendix 1. Standard errors are clustered by firm and time (year-quarter) following Petersen (2009) and Gow et al. (2010). Robust $\mathrm{t}$-statistics are reported in parenthesis. Significance level: *** $\mathrm{p}<0.01, * * \mathrm{p}<0.05, * \mathrm{p}<0.1$.

\begin{tabular}{|c|c|c|c|c|}
\hline \multirow[t]{3}{*}{ Variables } & \multicolumn{4}{|c|}{ Dependent Variable $=X R E T \_D R I F T$} \\
\hline & \multicolumn{2}{|c|}{ Make-to-Stock Firms } & \multicolumn{2}{|c|}{ Make-to-Order Firms } \\
\hline & [1] & [2] & [3] & [4] \\
\hline Intercept & $\begin{array}{c}0.0058 \\
(0.48)\end{array}$ & $\begin{array}{c}0.0041 \\
(0.34)\end{array}$ & $\begin{array}{c}0.0113 \\
(0.87)\end{array}$ & $\begin{array}{c}0.0114 \\
(0.89)\end{array}$ \\
\hline$B K L$ & $\begin{array}{c}0.0112 \\
(1.61)\end{array}$ & $\begin{array}{l}0.0112 \\
(1.60)\end{array}$ & $\begin{array}{l}0.008 \\
(1.18)\end{array}$ & $\begin{array}{l}0.008 \\
(1.19)\end{array}$ \\
\hline TONE & $\begin{array}{c}0.0218 * \\
(1.97)\end{array}$ & $\begin{array}{c}0.0228 * * \\
(2.06)\end{array}$ & $\begin{array}{c}0.0188^{* *} \\
(2.31)\end{array}$ & $\begin{array}{c}0.0188^{* *} \\
(2.32)\end{array}$ \\
\hline SUEAF1 & $\begin{array}{c}0.0100 \\
(0.89)\end{array}$ & & $\begin{array}{c}-0.0012 \\
(-0.19)\end{array}$ & \\
\hline SUEAF2 & & $\begin{array}{c}0.0051 \\
(0.37)\end{array}$ & & $\begin{array}{l}-0.0007 \\
(-0.11)\end{array}$ \\
\hline $\log (A S S E T S)$ & $\begin{array}{c}-0.0005 \\
(-0.35)\end{array}$ & $\begin{array}{c}-0.0002 \\
(-0.16)\end{array}$ & $\begin{array}{c}-0.0003 \\
(-0.24)\end{array}$ & $\begin{array}{c}-0.0004 \\
(-0.27)\end{array}$ \\
\hline$B M$ & $\begin{array}{l}0.005 \\
(0.72)\end{array}$ & $\begin{array}{l}0.005 \\
(0.71)\end{array}$ & $\begin{array}{c}-0.0035 \\
(-0.39)\end{array}$ & $\begin{array}{c}-0.0034 \\
(-0.38)\end{array}$ \\
\hline$S T D \_E A R N$ & $\begin{array}{c}0.0001 \\
(0.00)\end{array}$ & $\begin{array}{c}-0.0024 \\
(-0.05)\end{array}$ & $\begin{array}{c}-0.0525 \\
(-1.48)\end{array}$ & $\begin{array}{l}-0.0523 \\
(-1.46)\end{array}$ \\
\hline XRET_PRELIM & $\begin{array}{l}-0.003 \\
(-0.26)\end{array}$ & $\begin{array}{c}-0.0017 \\
(-0.14)\end{array}$ & $\begin{array}{c}0.014 * * \\
(2.05)\end{array}$ & $\begin{array}{c}0.0139^{* *} \\
(2.03)\end{array}$ \\
\hline No. Obs. & 4,829 & 4,829 & 13,987 & 13,987 \\
\hline R-squared & $0.28 \%$ & $0.26 \%$ & $0.30 \%$ & $0.30 \%$ \\
\hline
\end{tabular}

Sources: Thomson Reuters, Compustat, I/B/E/S, CSRP, Amenity Analytics, QMA. As of 3/15/2020. 